\title{
ERRATUM
}

Eric M. Shepard · Gregory A. Juda $\cdot$ Ke-Qing Ling Lawrence M. Sayre · David M. Dooley

\section{Cyanide as a copper and quinone-directed inhibitor of amine oxidases from pea seedlings (Pisum sativum) and Arthrobacter globiformis: evidence for both copper coordination and cyanohydrin derivatization of the quinone cofactor}

Published online: 7 May 2004

(C) SBIC 2004

\section{J Biol Inorg Chem (2004) 9:256-268}

In the print version and in the online pdf version of this article Hansenula polymorpha was not italicised in line 6 of the last paragraph on p. 257 and on p. 260 Eq. 3 appears twice. The publisher regrets these errors. The HTML version is correct.

The online version of the original article can be found at http:// dx.doi.org/10.1007/s00775-004-0522-7

E. M. Shepard · G. A. Juda · D. M. Dooley $(\varangle)$

Department of Chemistry and Biochemistry,

Montana State University, Bozeman,

MT 59717, USA

E-mail: dmdooley@montana.edu

Tel.: + 1-406-9944371

Fax: + 1-406-9947989

K.-Q. Ling · L. M. Sayre $(\bowtie)$

Department of Chemistry,

Case Western Reserve University,

Cleveland, $\mathrm{OH} 44106$, USA

E-mail:1ms3@po.cwru.edu

Tel.: + 1-216-3683704

Fax: + 1-216-3683006 